\title{
Adoption of e-Government in Pakistan: Supply Perspective
}

\author{
Zulfiqar Haider ${ }^{1}$, Chen Shuwen ${ }^{2}$ \\ Dalian University of Technology, \\ Faculty of Management and Economics, \\ No.2 Linggong Road, Ganjingzi District, \\ Dalian 116023, Liaoning, P.R. China
}

\author{
Dr. Farah Lalani ${ }^{3}$, Dr. Aftab Ahmed Mangi ${ }^{4}$ \\ Department of Public Administration \\ Faculty of Social Sciences, \\ University of Sindh, Jamshoro \\ 71000, Sindh, Pakistan
}

\begin{abstract}
Electronic Government, also known as eGovernment, is a convenient way for citizens to access e- services and to conduct business with the government using the Internet. It saves citizens and the government both time and money. This study examined adoption of e-Government supply side by looking at the UTAUT as a model of technology acceptance. Furthermore, specific variables that were proposed to moderate relationships within the UTAUT were analyzed including locus of control, perceived organizational support, affective and normative commitment, and procedural justice. Data from one sample indicated that in general, the UTAUT model was supported, however, the moderators proved non-significant. Implications are discussed for the technology acceptance process as technologies are implemented within countries and suggestions for future research in this area are discussed. This research sought to demonstrate the robustness of trust-based UTAUT to address e-Government adoption concerns. As a consequence, it was the responsibility of the researcher to select research questions, operational variables, research approaches, and research techniques, within the scope of the study. The research hypotheses formulated in this study were based on the technology acceptance literature covering the original UTAUT model with the inclusion of the trust construct. This quantitative study was conducted with help of Unified Theory of Acceptance and Use of Technology (UTAUT) model.
\end{abstract}

Keywords-e-Government; adoption; Supply; UTAUT model; Pakistan

\section{INTRODUCTION}

The implementation and use of technology in government agencies, in order to improve access to information, procedures and services offered to citizens; increase the efficiency and effectiveness of public administration and to substantially increase transparency and citizen participation are the main concepts related to electronic government. The implementation of electronic government should be viewed as the right of citizens to interact electronically with government. This implies that administrations are interrelated to simplify procedures, services and procedures.

At present the use of new technologies is fundamental to support the transformation processes that are being developed tool. ${ }^{[1]}$. The Electronic Government includes all initiatives that enable the migration of information (procedures and services of paper-based manual procedures) of computerized procedures; accessing them through multiple channels such as the Internet, mobile devices, Citizen Service Centers, among others ${ }^{[2]}$

Before analyzing the role played by the background of UTAUT, begin by exposing the resulting relationships between the component variables of the model used, verifying the impact of expectancy and effort expectancy result on the intended use of the platform e-Government. According to the results achieved when a person has freedom in the decision to adopt e-Government platform it will if considered useful and easy to use; also in line with social influence plays no significant role in the adoption of e-Government. As suggested in the literature, in the case of voluntary adoption environments, attitudes correlate with behavioral intention and using this according to the results achieved and in line with previous studies. According to UTUAT model, it is also important particular for public sector employees have a professional skills with positive behavior to provide best e-Government services to their citizens ${ }^{[3]}$. Even though earlier researchers missed to identify to know the important factors related to supply side development. But it is crucial to analyze the factors that implementing the adoption of supply-side of e-Government in developing countries like Pakistan.

PROCESS FOR E-GOVERNANCE

(Experience \& Recommendations for Strategic initiative)

TRANSACT: Providing Government services accessible online to all type of users.

- Government can create web portal that allow users to conduct transactions online.

- As the private sector in developing countries is beginning to make use of the internet to offer e-commerce services.

- Government will be expected to do the same with their services.

- Potential cost savings, accountability thorough information logs and productivity improvement will be important drivers.

Recommendations for Transact Projects:

1. Target audiences that will have immediate use for the online services

2. Enlist the support of those who will be using the site and address the concerns of government workers whose role will change as result of the innovation.

3. Integrate e-Governance with process reform, streamlining and consolidating processes before putting them online.

4. Create a portal for transact services.

Fig. 1. e-Government Pakistan (fbr.gov.pk)

Governments are making a major effort to develop systems providing public services that come to complete the traditional. The effective use of the platform will be caused both by the intention of using it as the belief that there have both human 
resources infrastructure and personnel needed to help if necessary ${ }^{[4]}$.

The Electronic Government, in its broadest sense, is developed mainly based on four categories of stakeholders:

- Citizens and organizations or civic associations.

- The private sector, through individual and corporate operators.

- The state, through state employees and / or other government and state agents.

This work aims to fill this gap by presenting a more holistic view of e-Government development in the municipalities of the metropolitan area of Sindh using this index for telecommunications infrastructure households, the index of the cultural capital of the population and the rate evolution of the websites of the municipalities of the metropolitan area; in this way you will know if the benefits of e-Government reach most of the citizens of these municipalities.

\section{THEORETICAL FOUNDATION}

The obstructions are abridged in the lack of involvement in the utilization of IT, lack of mindfulness and information of eGovernment administrations and lack of trust in government and IT alike. Utilizing the UTAUT, investigated the supply side factors that influence the use of citizen driven eGovernment administrations in Pakistan ${ }^{[5]}$. The outcomes demonstrated that factors, for example, encouraging conditions, companion impact, execution hope, and exertion anticipation, clarify the conduct of Pakistani citizens towards the use of such e-administrations. The study additionally indicated different factors, for example, society, trust, which was excluded in this connection, yet in future studies in light of their significance.

Also in distinctive connection, investigated utilizing the UTAUT the supply-side factors that influence the behavioral expectation of people to use citizen driven and e-Government administrations in Pakistan ${ }^{[6]}$. The outcomes demonstrated three compelling factors, execution anticipation, social impact, and encouraging conditions ${ }^{[7]}$. The study likewise indicated different factors, for example, society, which was excluded in this connection, yet in future studies in view of its significance. Talked about the factors influencing the citizens' plan to adopt and utilization citizen-driven e-Government administrations, especially the difficulties confronting the Information Technology move in the Pakistan on a substantial scale. The outcomes demonstrated that among those factors, nature of administration, dispersion of advancement, PC and information literacy, society, lack of mindfulness, specialized base, site outline, and security, which influence the citizens to adopt egovernment administrations in the same setting ${ }^{[8]}$.

The e-Government initiatives aimed at rural and marginal urban areas, as well as groups that have traditionally been disadvantaged, such as indigenous peoples and women, should aim at improving their quality of life and work. They should also aim to reduce poverty by encouraging participation in political processes, the design of effective mechanisms to address the most pressing needs and opening spaces for insertion in the labor and productive sphere. Many public services are offered online for citizens to use. Citizens are now able to pay their property and income taxes online, file their tax returns, apply for unemployment services, renew their drivers' licenses, research political candidates or elected officials and their platforms, file complaints, register to vote, and participate in electronic voting ${ }^{[9]}$

In Pakistan citizens can also search public websites and library websites, change their addresses, register vehicles, file police reports, apply for jobs, and download official forms on the Internet. According to Asgarkhani (2007), the benefits of eGovernment include providing expedient government services to citizens and businesses, improving the economy, allowing for greater public access to information, empowering citizens, and making the government more accountable to its citizens. Yet, these benefits are not equally distributed ${ }^{[10]}$.

\section{Effect I: eGovernment services stimulates broadband adoption}

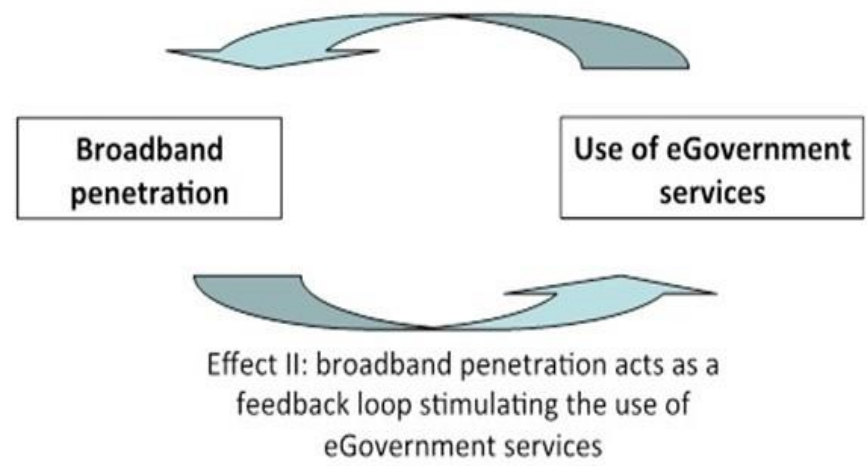

Fig. 2. e-Government services broadband adoption

Official efforts for the establishment of e-Government in Pakistan started in the year of 2003 along with the establishment of an organization named "Pakistan Digital" by the government. Pakistan Digital is liable for all e-commerce and electronic government services in the country. From the get go, this association was accountable for identifying the technological and information requirements for different agencies of government in Pakistan in order to contribute in electronic government ${ }^{[11]}{ }^{[12]}$. According to the recent study, the electronic government of Pakistan is still in the beginning phase of building e-services that concentrate on providing data to users.

In Pakistan many government services are provided online and each year it appears that new services are added. According to Aerschot \& Rodousakis, 2008 Common government services provided online include: downloading forms, obtaining information, using job services, searching for library books, submitting forms, making payments to different government entities, interacting with the tax office, requesting documents, completing change of address forms, statements to the police, and car registration. Citizens may also pay parking tickets; request passports, drivers' licenses, and birth certificates; and request other replacement documents online. Many of these service tasks can be accomplished in minutes with several key strokes ${ }^{[13]}$. 


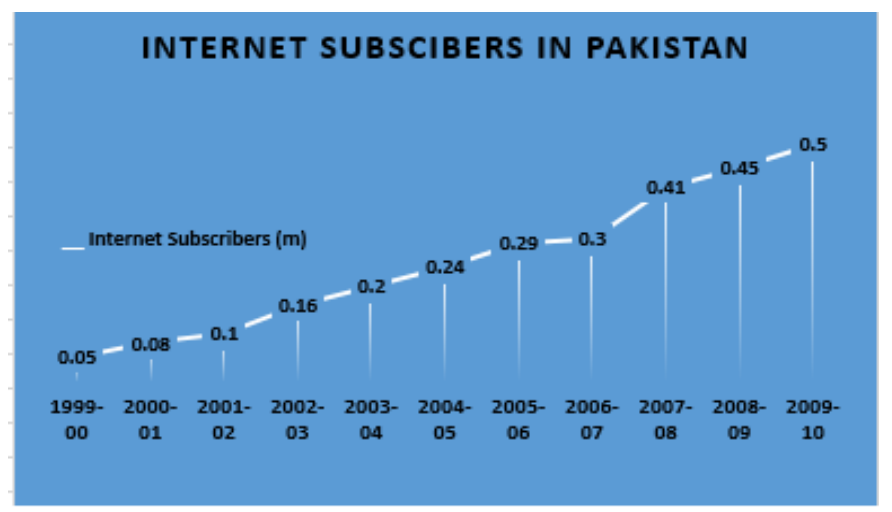

Fig. 3. MS Excel (output) - Source PTA (Pakistan Telecommunication Authority

\section{USE OF E-GOVERNMETN SERVICES IN PAKISTAN}

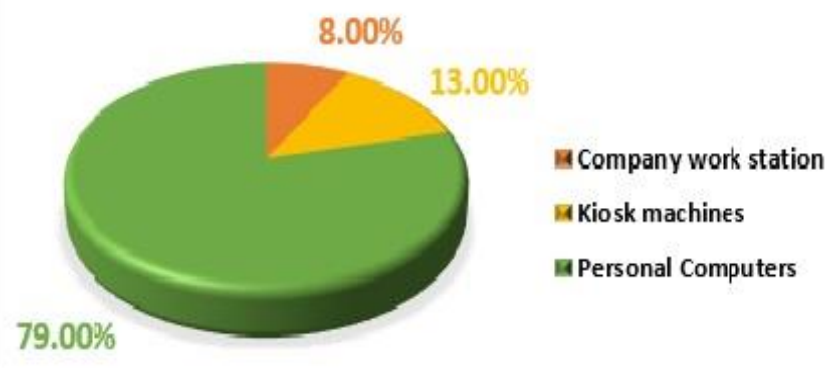

Fig. 4. use of e-Government services in Pakistan

The paper also verifies the significant effect of knowledge on social influence, and self-efficacy and assistance on enabling conditions, but the convenience of the latter. Nor is the effect of self-efficacy on the expectation of effort and convenience of enabling conditions observed. Being selfefficacy perceived the key cognitive effort, history can understand that this is not related significantly with the expectation of effort. Regarding the convenience that it is a voluntary service causes this is linked to the expectation of effort but not the enabling conditions. The services and facilities provided by the e-Government relate to the idea that benefit from its use will be easy, but not there technology and support required if needed citizens.

The economic and social crisis in much of Pakistan continually question the current organization and structure of public administration in the supposed interest of improving our competitiveness ${ }^{[14]}$. To achieve this, governments are taking measures of various kinds. On the one hand, they are delegating some of its functions to private entities (taxes and fees charges by banks and savings banks, for example); on the other, are trying to arrange with the public are made increasingly without resorting to personal interaction with the administration, thereby promoting self as usual in other economic sectors.

\section{Literature RELATED TO E-SERVICES AdOPTION}

In Pakistan, citizens contact the government for personal concerns and problems, and they also contact the government to influence public policy, and to locate information about government services and benefits (Cohen, 2006) ${ }^{[15]}$. The literature also points out that many of the services offered online do not allow citizens to conduct entire transactions or complete their tasks from beginning to end (Rodousakis \& Santos, 2008). Citizens are forced to mail documents or go in person to a government agency when they would prefer to conduct their business online ${ }^{[16]}$. Possible reasons that entire transactions cannot be conducted online are the need to prevent fraudulent activity by identifying those applying for services, the funds are not available to make government websites fully functional or capable of completing transactions online, and to keep government employees employed ${ }^{[17][18]}$.

A good deal of research is available that has investigated the determinants for accepting information technology services in offline and online environments. Evidence from the literature shows that there are two main approaches for Information Technology acceptance research (Harrison et al., 1997; Hernandez and Mazzon, 2007; Taylor and Todd, 1995a). One of the most widely used approaches works on developing strategies to examine IT adoption. This approach suggests and uses models and behavioral theories that are drawn from psychology, which act as a foundation for information systems research, such as, the Technology Acceptance Model (TAM) and Theory of Planned Behavior (TPB) (Harrison et al., 1997). The theory of planned behavior, for instance, is famously established and is frequently used in various settings for research into IT adoption to determine intention behavior ${ }^{[19]}$.

TABLE I. FREQUENTLY USED IN VARIOUS SETTINGS FOR RESEARCH

\begin{tabular}{|l|l|l|l|l|}
\hline \multicolumn{5}{|c|}{$\begin{array}{c}\text { Cities with websites } \\
(n=2376) \\
\text { Mean }\end{array}$ St. deviation $\begin{array}{c}\text { Small cities with websites } \\
(n=725) \\
\text { Mean } \quad \text { St. }\end{array}$} \\
\hline Area 2000 & 1184.22 & $\mathbf{2 7 6 9 . 8 4}$ & 1349 & 6187.51 \\
\hline Population 2006 & 114685 & 348657.26 & 33002 & 100519.73 \\
\hline Population 2005 & 113400 & 346021.19 & 33230 & 101248.95 \\
\hline Population 2000 & 107195 & 329418.83 & 32837 & 99767.50 \\
\hline Population 1990 & 94013 & 296877.19 & 31121 & 95364.19 \\
\hline $\begin{array}{l}\text { Population density } \\
\text { per Square mile }\end{array}$ & 273.67 & 1934.04 & 63.61 & 184.99 \\
\hline No. of households & 40061 & 117041.83 & 12643 & 38260.89 \\
\hline
\end{tabular}

If e-Government or information technology is to facilitate an organizational "transformation" in the public sector, then it will also require a more critical examination of the way we are currently measuring such initiatives. Public agencies will need to expand their thinking about e-Government, and incorporate initiatives that build IT capacity into organizations. Finally, public organizations will need to move beyond the current ecommerce model and begin to look at how the Internet can be used between citizens, the business community, and internally between government agencies. Small cities tend to be challenged in the digital domain to deliver efficient services to their citizens, realize the potential of information and communications technology (ICT), and grant citizens large participatory roles in their governance ${ }^{[20]}$. E-government activity should bridge the communication gap between elected 
officials and stakeholders both more diverse and more extensive ${ }^{[21]}$. Barriers in supply side of e-Government in Pakistan were observed from a survey result.

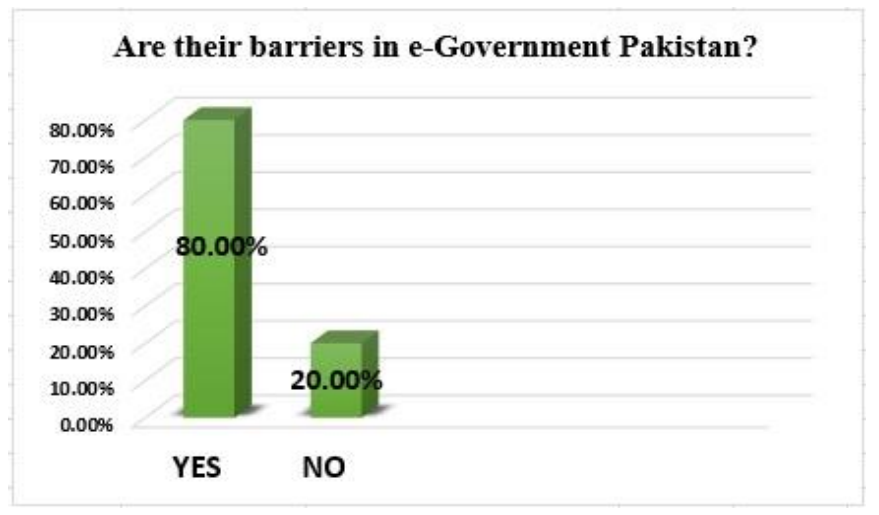

Fig. 5. Barrier in e-Government

Availability of e-Government services as part of an egovernment 2.0 program had a $28 \%$ usage average, the lowest of the three benchmarks. Future research could be required as the availability of e-Government services as part of egovernment 2.0 program increases ${ }^{[22]}$. Research by local government Information Technology professionals in areas such as rich site summary (RSS) as a means of feeding posted information through newsfeeds and e-mail programs and improving access to city services from mobile devices is becoming as it becomes more common. While all of the cities explored in this study had an official presence on the World Wide Web, only 10 of those cities optimized the websites for viewing on mobile devices. All of the cities which utilized third-party website development were optimized for mobile viewing ${ }^{[23]}$. A recommendation would to add mobile device viewing optimization as part of a third-party e-Government program development. And finally the a return on investment analysis by elected local government officials on using kiosks for access to e-Government services from locations conveniently located throughout the city. A major obstacle could be the cost of kiosks. A recommendation for a kiosk solution could be following the example of Farmington, Sindh's kiosk stations. Farmington purchased 21inch Android touch screen tablets with Site Kiosk software installed. The kiosk provides access to the e-Government services available on the city's website. Total cost of ownership was less than $\$ 400$ per location ${ }^{[24]}$.

Farmington has 4 kiosk locations at public buildings throughout the city. 147 Further researches on whether this is a viable solution for other small-sized rural cities could be conducted. ${ }^{[25]}$. The determination of this qualitative study was to identify, describe, and analyze user adoption patterns of egovernment services in small-sized cities. To fulfill the effort of the study, this research utilized a multiple-case study design to examine user adoption patterns that remain undocumented in fourth class, third class, and constitutional charter cities in Sindh, Pakistan. The goal of this study was fulfilled through content analysis of the cities' official websites and social media sites. The results of this study suggest that while e-government services for small-sized rural cities still lag behind larger city and state government agencies, the local government agencies utilizing companies that specialize in the development of government to citizen applications for the development of their e-government services were scored the highest for the number of e-Government services offered.

The government agency websites developed by those companies were easier to navigate and offered the most services. Additionally, the sites were accessible and optimized for use on portable devices. Additionally, the results of the current study support Baumgarten and Chui's (2010) assertions that Web 2.0 tools should be incorporated with e-government tools to provide e-Government services that promote citizen empowerment and promote collaboration between tax payers and government agencies. However, the results of this current study showed that the digital divide characteristic of limited access to high-speed broadband Internet service was not a factor for the cities explored. With readily available access to high-speed broadband Internet, the question was raised as to why e-government services were not being offered consistently across the cities explored in this study.

This supports Christopher's (2009) assertion that the greatest barrier to delivering e-government 2.0 services is not just a factor of the digital divide but also a factor of cost and limited government budgets. It would seem that the cost of implementing an effective e-government 2.0 program with egovernment services which empower citizens could be factor as to why adoption patterns is low for small-sized rural government agencies ${ }^{[26]}$ Again this becomes apparent in the results of this study that show the cities that utilized third-party e-government program implementation have the highest number of services available to their citizens. Consistent with research literature which suggests that social media venues can be used to create lines of communication and interaction between government agencies and citizens (Auer, 2011; Bryer, 2011; Dadashzadeh, 2010; Hand \& Ching, 2011; Mann, 2010) depending on rates of user adoption (Colesca, 2009), this research showed that the cities which utilized social media sites had interaction and collaboration with citizens. Lin and Lu's (2011) research showed that having an understanding of the citizens' 149 willingness to accept social media could enable elected government officials to develop social media sites that target the needs of the users. Of the cities explored in this study, 13 utilized some form of social media. In some cases, such as Farmington, the people following the social media sites outnumbered the total population of the city. This shows that if the city posts information that is relevant to the followers, the citizens of that city and surrounding areas will not only follow that information but also become participants by commenting and asking questions on the sites. This is the kind of collaboration that could be used to empower citizens in the democratic process. There may be multiple audiences that can benefit from this research. For example, the findings of this study may be of interest to local government elected officials, government agency departments, government IT professionals, and city citizens. Local government officials, government IT professionals, and government agency departments can use this study as a guide as to which services are being offered by other cities and which tools work best for empowering citizens. City residents could use this to see which services could be made available which could better serve the general public and 
empower citizens as an active participant in local government decision making processes. Overall, this study extends the body of knowledge on citizen participation through egovernment services and could provide supporting data for leaders in local small-sized government agencies to advocate for and implement government transparency and citizen empowerment.

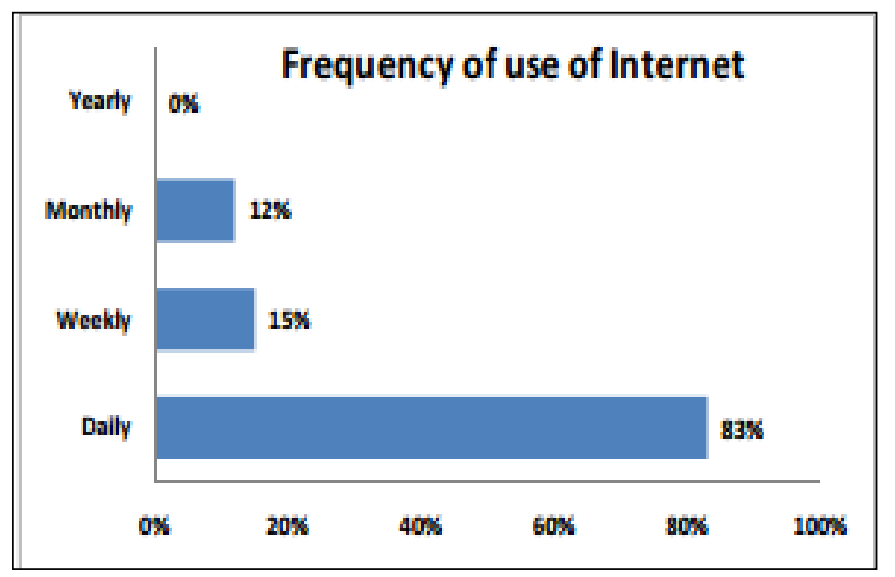

Fig. 6. Frequency of use for internet

\section{PURPOSE OF THE STUDY}

The purpose of this qualitative study was to identify, describe, and analyze user adoption patterns of e-Government services in small-sized cities. To fulfill the purpose of the study, this research utilized a multiple case study design to examine user adoption patterns that remained undocumented in fourth class, third class, and constitutional charter cities in Pakistan with populations between 12,000 and 20,000 citizens [27]

The goal of this study was fulfilled through content analysis of the city's official websites and social media sites. An exploratory qualitative research approach was an appropriate method for exploring the purpose of the study because of a lack of confirmed and well established e-government services and user adoption patterns in the population (Shank, 2006). Quantitative study for internet access in Pakistan showed the following results.

\section{IT Barriers: Insufficient access to Internet}

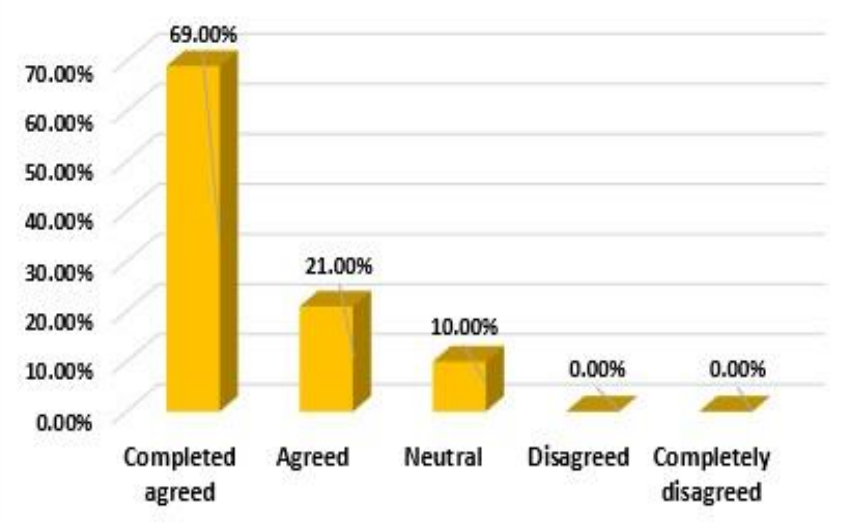

Fig. 7. I T Barriers

\section{RESEARCH QUESTION}

The objective of first research question

1) Identify user adoption patterns of e-Government services in small-sized cities in Sindh. The objective of second research question.

2) Identify what a content analysis of user adoption patterns of e-Government services indicate about citizen empowerment opportunities in small-sized cities in Sindh.

Data was collected by analyzing user adoption patterns of the researched cities social media sites and available citizen satisfaction surveys. To evaluate the findings of this research, each city that made up the population of the study was treated as a separate case study. Since each of the sample cities were treated as a separate case study, an evaluation of the findings focusing on the 10 semi-structured based on the three benchmarks of e-participation established by the United Nations 2010 survey (United Nations, 2010) are listed below. Fulton. Fulton offers some of the e-Government services expected from a small sized city. The official website was difficult to navigate when looking for specific documents to download.

\section{SIGNIFICANCE OF THE STUDY}

The Adoption of e-Government in Pakistan is important in empowering citizens and making them an integral part of the democratic process. There was evidence that technological advances in e-Government, especially ICTs, have been utilized to enhance dissemination of information and citizen participation in government processes (e-tax system from Federal Board of Revenue (FBR). However, the body of evidence on its adoption and usage by citizens remained weak. Developing an in-depth understanding of the adoption patterns of e-Government in small-sized rural cities in Pakistan was the goal of this study. Findings from this study may be useful for promoting citizen empowerment within small-sized rural cities. This goal was accomplished by understanding the barriers to empowerment through e-Government is presented and making recommendations on how to overcome those barriers to user adoption of e-Government in small-sized cities in Pakistan.

Regarding the operation UTAUT model the expected result (path $=0.3102, \mathrm{t}$-value $=2.7378$ ) and the expectation of effort (path $=0.4204, \mathrm{t}$-value $=4.2514)$ directly affect the intended use, while social influence no such significant effect (path = 0.0531, t-value $=0.5696$ ). Finally, both the intended use (path $=0.2719$, $\mathrm{t}$-value $=3.2215$ ) as enabling conditions (path $=$ 0.2118 , $t$-value $=2.3349$ ) significantly affect the effective use of the platform of e-Government.

\section{IMPLICATIONS, RECOMMENDATIONS, AND CONCLUSIONS}

The basis of this study was an examination of user adoption patterns of e-Government services in small-sized cities in Sindh- Pakistan. The problems addressed were a gap in identifying the user adoption patterns of e-government services and what a content analysis of user adoption patterns of eGovernment services indicated about citizen empowerment opportunities. Despite the policy calling for government transparency, citizen interaction, and government openness 
through the use of e-Government 2.0, little has been done in this area for small-sized cities ${ }^{[28]}$. Particularly those with limited access to high-speed Internet service ${ }^{[29]}$. This phenomenon was particularly true for e-Government, the one section of e-Government with the lowest adoption rate ${ }^{[30]}$ and the greatest potential for citizen empowerment. The purpose of this qualitative multiple-case study was to identify, describe, and analyze user adoption patterns of e-Government services in fourth class, third class, and constitutional charter cities in Sindh, Pakistan.

For this research paper, a qualitative approach with a multiple case study design was used to answer the research questions. Due to the limited availability of relevant research data on e-Government and e-government initiatives for smallsized rural cities [31]. According to Akbulut-Bailey, 2011; Bonsón, Torres, Royo, \& Flores, 2012; Parvez, 2008, this study was exploratory in nature in order to uncover relevant information about the topic. Exploratory research was a viable option for the research of citizen empowerment through eGovernment services (Zikmund, Babin, Carr, Griffin, 2010). This study is non 139 experimental in nature investigated the challenges, practices, and strategies related to the delivery of egovernment services as observed in the 23 small-sized cities and 4 census designated places of Sindh that are the focus. Data collection included relevant and available sources such as documentation and observations from the city's official website and social media presence. Data collection focused on $10 \mathrm{semi-}$ structured questions that were used to identify and measure egovernment services offered by small-sized Sindh cities which were the focus of this study.

According to our research, if governments want to increase both the intent and the effective use of e-Government in the Administration should develop actions of public marketing to improve the perceptions that people have about their expectations of use, on its ease of use and on the existence of willing and able to solve any problems that arise during use professional support. The work presented confirms the relevance of these elements from the perspective of managed also highlighting the importance for management is considering these 4 factors: aversion citizen expressing the personal interaction with the Administration, the degree of confidence that holds in the tool, receive assistance and convenience you see in the use of e-government.

Consequently, aversion to personal interaction is a key segmentation criteria that should be used by management to identify population groups of citizens who develop a different behavior in relation to the use of e-Government. It is recommended, therefore, to distinguish groups in the population according to the degree of aversion (high or low). In both segments is advisable to implement actions that enhance communication with messages on the citizen trust in eGovernment tools and security in obtaining assistance. However, since the motivation for use in population with low aversion to personal interaction ventures to lower priori, the effort it must also focus on showing convenience (less effort and better conditions of service provision).

\section{A. Implications}

Two research questions guided the purpose of this study.
The findings represent a contribution towards a better understanding of how small-sized local government agencies in Sindh are empowering citizens through e-Government services. Consistent with the purpose of this study, Research Question One (Q1) asked: what are the user adoption patterns of eGovernment services in small-sized cities in Sindh? Research question two (Q2) identified that cities which contracted thirdparty e-Government software developers to create an eGovernment 2.0 portal which incorporates e-Government tools for user collaboration, communication, and participation have the highest user adoption rates.

Additionally, e-Government services are more likely to be adopted by cities, which have a social media presence that promotes citizen participation ${ }^{[32]}$. The findings indicate that adoption patterns of e-Government services in small-sized cities, from most prevalent to least are, are based upon availability of e-Government services, communication between government agencies and citizens, and government transparency. A finding of this study is that cities, which outsourced website development with integrated e-government and e-Government tools, have higher user adoption and availability. D’Agostino's et al. (2011), Park (2007), and all agree that static websites that are typical of small-sized local government agencies are ineffective in delivering the eGovernment services expected by citizens in the digital age. In fact, the rate of adoption of ICTs to support citizen empowerment in the form of e-Government was assessed as "fair" to "low" in the extant ${ }^{[33,34]}$.

The implication of this current research may indicate that 141 if small-sized local government agencies utilize the services of companies that specialize in the development of government to citizen applications for the development of their e-Government services, they could improve the availability of services that could empower citizens. One interesting finding of the study is that within the past 5 years high-speed broadband Internet service has become readily available in the cities explored in the study. Baird, Zelin, and Booker (2012) found that there seems to be an increasing disparity in the development and adoption of e-Government programs, especially in small-sized cities, due to the digital divide. The implication of this current research may indicate that one of the primary factors that was found to increase the digital divide gap, lack of high-speed broadband Internet, did not seem to be a factor in the cities and census designated places explored in the study.

Every one of the 23 cities, information is unknown on the census designated places, provided access to high-speed broadband Internet in the Public Libraries as well as other public accessible buildings. Past research has demonstrated that even though the Internet offers open access to political information and services, this primarily benefits those with easy access to the high-speed Internet service (Schwester, 2009).

For example, Whitacre (2010) indicated that rural smallsized communities are at a political disadvantage and cannot take advantage of modern ICTs for e-government services due to lack of accessible and affordable broadband Internet service. Additionally, Alemanne et al. (2011) stated that the rural 
community Public Library should be the leader in broadband high-speed Internet access for the location they serve ${ }^{[34]}{ }^{[35]}$.

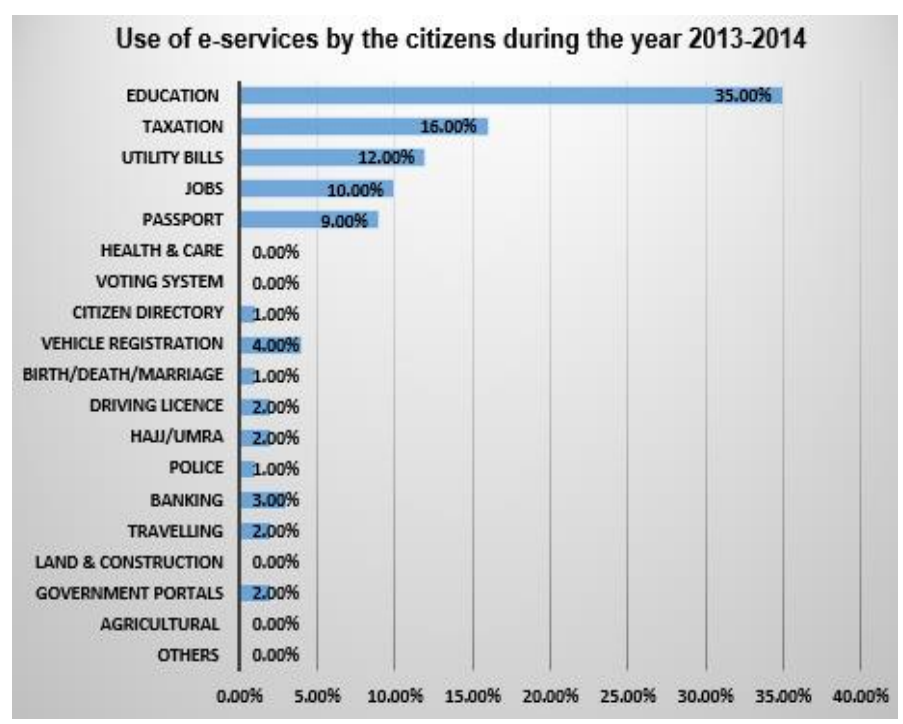

Fig. 8. Use of e-services by the users

The Taylor et al. (2012) indicated that Public Libraries which offer access to high-speed Internet not only improve availability of e-Government 142 services, but they also often have staff available that can help train the user on how to best utilize those services. The cities explored in this study all have broadband Internet service with public access computers at their local Public Library and Gautam et al. (2013), explained that the few remaining areas without broadband Internet service are currently constructing broadband infrastructures through the broad band Now grants. Research Question Two (Q2) asked: what does a content analysis of user adoption patterns of e-Government services indicate about citizen empowerment opportunities in small-sized cities in Sindh? Research question two (Q2) identified that the greatest citizen empowerment opportunity identified was the use of social media. While social media sites do take some time to create and manage, they are free tools that provide citizens with a means of two-way communication when used correctly.

The citizens become an active participant in the democratic processes of the local government agency. Questions can be asked and feedback provided in real-time. Additionally, social media can be used to disseminate news and events, take surveys, and solicit public input. Research showed that social media venues can be used to create lines of communication and interaction between government agencies and citizens. Depending on rates of user adoption (Colesca, 2009). The implication of this current research helps confirm the existing research theory that social media does increase communication between the government agencies and citizens, based on the observations of the cities explored in this study ${ }^{[36]}$, [37] researched the challenges and obstacles that may be faced when government agencies implement social media. However, based on the findings of this study, social media is the preferred method of online communication between 144 citizens and government officials. The development of eGovernment must be assumed as an evolutionary process into five phases (presence, interaction, transaction processing and citizen participation) and must meet four dimensions (external, promotion, internal and relational). These phases and dimensions are not interdependent nor need to complete one to start another. Each has a different purpose and requires different requirements in terms of organization, costs, needs knowledge and level of ICT use.

Although the implementation of e-government requires the availability of a technological infrastructure, this alone does not achieve the success of the transformation. To do human resources are required mastery of concepts of e-government, given their potential and level of technological literacy and during deployment managers at various levels of government develop a high motivation for change and achieve leverage advantages of e-government and minimize, during implementation, possible disadvantages that may arise.

\section{B. Recommendations}

The nature of exploratory research is that it raises more questions than answered and is often conducted to define research questions (Yin, 2009). Exploratory qualitative research approach was an appropriate method for exploring the purpose of the study because of a lack of confirmed and well established e-Government services and user adoption patterns in the sample population ${ }^{[38]}$. In this multi-case study qualitative research project, some questions were answered while others were partially answered and provide opportunities for further research. In addition to extending the body of knowledge about e-Government 2.0 programs and citizen empowerment through 144 e-Governments in small-sized rural Sindh cities, there are practical applications of this study in promoting citizen collaboration and participation. This section will address the recommendations for practice. The recommendations drawn from this study are relevant to elected local government officials, local government IT professionals, and the citizens of small-sized cities.

We have talked about a few obstructions in the development and movement of e-government. Keeping these factors aside, hierarchical and political factors are also, will remain the primary hindrances towards this new and better government at any rate in the creating countries. The governments who have the capacity to handle the red tape and political weight will be ensured pioneers in this type of administration. In future explores, the model proposed in this paper can be operational to limited down demand and supply side obstructions to add to a suitable system to further advance this manifestation of administration. Besides, more nation particular studies can be led to further enhance the proposed model.

\section{Conclusion}

The implementation of e-Government has been proven to be a convenient and effective way to boost productivity of government agencies and empower metropolitan area citizens by improving communication and promoting government transparency. However, the adoption of e-government services by citizens is inconsistent, at best, across the federal, state, and city government agencies. Visiting websites of smaller cities, it was clear to see that their e-Government initiatives consists of little more than just a static website with little to no online egovernment services. Elected officials of small-sized rural 
cities operate under pressure from internal and external stakeholders to not only create government transparency through e-government initiatives but to also increase user adoption of the programs that are part of e-Government initiatives. This multiple case study qualitative study described how municipalities use present e-government adoption patterns in small-sized cities to generate user adoption and citizen empowerment.

The research questions were generated based on a comprehensive literature review and with the purpose of defining the approach for the present study. Consistent with the purpose of this study, the two guiding research questions were developed. A qualitative multiple-case study design was chosen because of the depth of understanding of the phenomena under study afforded to the researcher. This research study provided a better understanding of how local government 18 elected officials would use present egovernment adoption patterns in small-sized cities to raise user adoption and to raise citizen empowerment.

Availability of e-democracy services as part of an egovernment 2.0 program had a $28 \%$ usage average, the lowest of the three benchmarks. Future research could be required as the availability of e-democracy services as part of an egovernment 2.0 program increases. All of the cities which utilized third-party website development were optimized for mobile viewing. This supports Christopher's (2009) assertion that the greatest barrier to delivering e-Government services is not just a factor of the digital divide but also a factor of cost and limited government budgets. There may be multiple audiences that can benefit from this research.

\section{REFERENCES}

[1] Layne K, Lee J. Developing fully functional Egovernment: A four stage model [J]. Government information quarterly, 2001, 18(2): 122-36.

[2] Bokhari H, Khan M. Digitisation of electoral rolls: analysis of a multiagency e-government project in Pakistan; proceedings of the Proceedings of the 6th International Conference on Theory and Practice of Electronic Governance, F, 2012 [C]. ACM.

[3] Lammers R. The Adoption of Open Standard Inter Organizational Systems [D]; University of Twente, 2010.

[4] Fang Z. E-government in digital era: concept, practice, and development [J]. International journal of the Computer, the Internet and management, 2002, 10(2): 1-22.

[5] Haider Z, Shuwen C, Panhwar K N. Demand for e-Government Adoption in Pakistan [J]. Public Policy and Administration Research, 2015, 5(5): 115-31.

[6] Ahmad M O, Markkula J, Oivo M. Factors influencing the adoption of e-government services in Pakistan; proceedings of the Proceedings of the 9th European, Mediterranean \& Middle Eastern Conference on Information Systems, F, 2012 [C].

[7] Norris D F, Reddick C G. Local e-government in the United States: transformation or incremental change? [J]. Public Administration Review, 2013, 73(1): 165-75.

[8] Rehman M, Esichaikul V. Factors influencing the adoption of egovernment in Pakistan; proceedings of the E-Business and EGovernment (ICEE), 2011 International Conference on, F, 2011 [C]. IEEE.

[9] Bird R M, Zolt E M. Technology and Taxation in Developing Countries: From Hand to Mouse [J]. Nat Tax J, 2008, 791-821.

[10] Starling G. Managing the public sector [M]. Cengage Learning, 2010.

[11] Wescott C G. E-Government in the Asia-pacific region [J]. Asian Journal of Political Science, 2001, 9(2): 1-24.
[12] Asgarkhani M. The Effectiveness of E-Service in Local Government: A Case [J]. Asymptotic and Computational Methods in Spatial Statistics, 2009, 22.

[13] Torres L, Pina V, Acerete B. E-government developments on delivering public services among EU cities [J]. Government Information Quarterly, 2005, 22(2): 217-38.

[14] Herani G M, Lodhi S A. Innovative technology, social and economic sustainability: Evidence from Pakistan [J]. 2008,

[15] Lean O K, Zailani S, Ramayah T, et al. Factors influencing intention to use e-government services among citizens in Malaysia [J]. International Journal of Information Management, 2009, 29(6): 458-75.

[16] Alruwaie M, El-Haddadeh R, Weerakkody V. A Framework for Evaluating Citizens' Expectations and Satisfaction toward Continued Intention to Use E-Government Services [M]. Electronic Government. Springer. 2012: 273-86.

[17] Gupta M, Jana D. E-government evaluation: A framework and case study [J]. Government information quarterly, 2003, 20(4): 365-87.

[18] Ebrahim Z, Irani Z. E-government adoption: architecture and barriers [J]. Business Process Management Journal, 2005, 11(5): 589-611.

[19] Halachmi A. E-government theory and practice: The evidence from Tennessee (USA) [J]. Frontiers of Public Administration, 2004, 24.

[20] Griffin D, Halpin E. An exploratory evaluation of UK local egovernment from an accountability perspective [J]. The Electronic Journal of e-Government, 2005, 3(1): 13-28.

[21] Kavanaugh A L, Isenhour P L, Cooper M, et al. Information technology in support of public deliberation [M]. Communities and Technologies 2005. Springer. 2005: 19-40.

[22] Veljković N, Bogdanović-Dinić S, Stoimenov L. Benchmarking open government: An open data perspective [J]. Government Information Quarterly, 2014, 31(2): 278-90.

[23] Kroski E. On the move with the mobile web: libraries and mobile technologies [J]. Library technology reports, 2008, 44(5): 1-48.

[24] Wagner C, Cheung K, Lee F, et al. Enhancing e-government in developing countries: managing knowledge through virtual communities [J]. The Electronic Journal of Information Systems in Developing Countries, 2003, 14(

[25] Aurigi A. Making the digital city: the early shaping of urban internet space [M]. Ashgate Publishing, Ltd., 2005.

[26] Mutula S M. Assessment of the e-readiness of small and medium sized enterprises in the ICT sector in Botswana, with special reference to information access [D]; University of Johannesburg, 2005.

[27] Davin E, Majidi N. Study on cross border population movements between Afghanistan and Pakistan [J]. Commissioned by the Office of the United Nations High Commissioner for Refugees (UNCHR), Kabul, 2009,

[28] Bertot J C, Jaeger P T, Hansen D. The impact of polices on government social media usage: Issues, challenges, and recommendations [J]. Government Information Quarterly, 2012, 29(1): 30-40.

[29] Alsufayri K. Universalising electronic government services: facing the digital divide challenge [D]; Auckland University of Technology, 2014.

[30] Sone J W. E-Governance in central Texas: patterns of e-gov adoption in smaller cities [D]; Texas State University, 2011.

[31] Anna Xiong J. Current status and needs of Chinese e-government users [J]. The Electronic Library, 2006, 24(6): 747-62.

[32] Bonsón E, Torres L, Royo S, et al. Local e-government 2.0: Social media and corporate transparency in municipalities [J]. Government information quarterly, 2012, 29(2): 123-32.

[33] Zambrano R. E-governance and development: Service delivery to empower the poor [J]. Social and Organizational Developments through Emerging E-Government Applications: New Principles and Concepts: New Principles and Concepts, 2009, 98.

[34] Ifinedo P. Factors influencing e-government maturity in transition economies and developing countries: a longitudinal perspective [J]. ACM SIGMIS Database, 2012, 42(4): 98-116.

[35] Carmichael L R, Mcclure C R, Mandel L H, et al. Broadband Adoption| Practical Approaches and Proposed Strategies for Measuring Selected 
Aspects of Community-Based Broadband Deployment and Use [J]. International Journal of Communication, 2012, 6(22.

[36] Owens C. Communicating an organisation's identity to library users: a case study within the New Zealand community library sector [D]; Unitec Institute of Technology, 2013.

[37] Susha I. Participation in open government [J]. 2015,

[38] Walts N. Native American Indian tribal college and university students: A qualitative study of the digital divide [D]; UNIVERSITY OF PHOENIX, 2011.

\section{AUTHOR PROFILE}

Zulfiqar Haider (Syed Zaidi) is working as an Assistant Professor in the Department of Public Administration, Faculty of Social Sciences, University of Sindh, Jamshoro, Pakistan. He is currently pursuing his Ph.D. degree at Dalian University of Technology, Dalian, China.

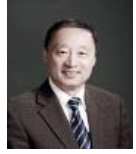

Prof. Chen Shuwen is working as a Dean at the School of Public Administration and also performing his duties as a doctoral programme supervisor at Dalian University of Technology, Dalian, China.

Prof. Dr. Farah Lalani is working as a Professor in the Department of Public Administration, Faculty of Social Sciences, University of Sindh, Jamshoro, Pakistan.

Dr. Aftab Ahmed Mangi is working as an Assistant Professor in the Department of Public Administration, Faculty of Social Sciences, University of Sindh, Jamshoro, Pakistan. 